\title{
Use of the Relaxometry Technique for Quantification of Paramagnetic Ions in Aqueous Solutions and a Comparison with Other Analytical Methods
}

\author{
Bruna Ferreira Gomes, ${ }^{1}$ Juliana Soares da Silva Burato, ${ }^{1}$ \\ Carlos Manuel Silva Lobo, ${ }^{1}$ and Luiz Alberto Colnago ${ }^{2}$ \\ ${ }^{1}$ Instituto de Química de São Carlos, Universidade de São Paulo, Avenida Trabalhador São-Carlense 400, \\ 13560-070 São Carlos, SP, Brazil \\ ${ }^{2}$ Embrapa Instrumentação, Rua XV de Novembro 1452, 13560-970 São Carlos, SP, Brazil
}

Correspondence should be addressed to Bruna Ferreira Gomes; brunalusp@gmail.com

Received 29 March 2016; Accepted 24 April 2016

Academic Editor: Peter A. Tanner

Copyright ( 2016 Bruna Ferreira Gomes et al. This is an open access article distributed under the Creative Commons Attribution License, which permits unrestricted use, distribution, and reproduction in any medium, provided the original work is properly cited.

\begin{abstract}
We have demonstrated that the relaxometry technique is very efficient to quantify paramagnetic ions during in situ electrolysis measurements. Therefore, the goal of this work was to validate the relaxometry technique in the determination of the concentration of the ions contained in electrolytic solutions, $\mathrm{Cu}^{2+}, \mathrm{Ni}^{2+}, \mathrm{Cr}^{3+}$, and $\mathrm{Mn}^{2+}$, and compare it with other analytical methods. Two different NMR spectrometers were used: a commercial spectrometer with a homogeneous magnetic field and a home-built unilateral sensor with an inhomogeneous magnetic field. Without pretreatment, manganese ions do not have absorption bands in the UV-Visible region, but it is possible to quantify them using relaxometry (the limit of quantification is close to $10^{-5} \mathrm{~mol} \mathrm{~L}^{-1}$ ). Therefore, since the technique does not require chemical indicators and is a cheap and robust method, it can be used as a replacement for some conventional quantification techniques. The relaxometry technique could be applied to evaluate the corrosion of metallic surfaces.
\end{abstract}

\section{Introduction}

Recently we demonstrated that time domain nuclear magnetic resonance (TD-NMR) is a very efficient and robust technique to quantify paramagnetic ions in a solution during in situ measurements of electrodeposition reactions $[1,2]$. It is also efficient in determining the solubility constant, $K_{\mathrm{sp}}$, of paramagnetic ions [3]. Such efficiency comes from the fact that this is a nondestructive analysis, which facilitates the coupling with other techniques [1-4]. Furthermore, operation and maintenance costs of the equipment are low, compared with current techniques for quantification.

This technique is performed with the known CPMG (Carr-Purcell-Meiboom-Gill) pulse sequence which measures the transverse relaxation time constant $\left(T_{2}\right)$ of the ${ }^{1} \mathrm{H}$ nuclei. When in an aqueous solution, the unpaired electrons of the paramagnetic ions interact with the ${ }^{1} \mathrm{H}$ nucleus in the solvent accelerating the relaxation process [5-8]. The variation of $T_{2}$ is inversely proportional to the concentration of the paramagnetic ions. This allows the construction of a calibration curve. This technique is known as relaxometry.

The objective of this work was to compare the relaxometry technique, for the quantification of the paramagnetic ions contained in aqueous electrolytic solutions, using the UV-Vis spectroscopic technique and data from the atomic absorption spectroscopy, which was obtained from the literature.

One possible application of this technique could be to monitor the process of corrosion, specifically corrosions taking place under the effect of a magnetic field, as it is already known that the magnetic field will alter the speed of the reaction $[1,2,9]$. 


\section{Experimental}

\subsection{Solutions}

2.1.1. $\mathrm{Cu}^{2+}$ Solution. The stock electrolyte solution was prepared with Milli-Q water, $0.1 \mathrm{~mol} \mathrm{~L}^{-1} \mathrm{CuSO}_{4} \cdot 5 \mathrm{H}_{2} \mathrm{O}$ (Synth), and $0.1 \mathrm{~mol} \mathrm{~L}^{-1} \mathrm{Na}_{2} \mathrm{SO}_{4}$ (ISOFAR) [1]. In order to obtain the calibration curve, this solution was diluted (using a $0.1 \mathrm{~mol} \mathrm{~L}^{-1} \mathrm{Na}_{2} \mathrm{SO}_{4}$ solution) down to a concentration of $10^{-5} \mathrm{~mol} \mathrm{~L}^{-1} \mathrm{Cu}^{2+}$.

2.1.2. $\mathrm{Ni}^{2+}$ Solution. The stock electrolyte solution (Watts solution) was prepared with Milli-Q water, $300 \mathrm{~g} \mathrm{~L}^{-1}$ $\mathrm{NiSO}_{4} \cdot 6 \mathrm{H}_{2} \mathrm{O}$ (Synth), $90 \mathrm{~g} \mathrm{~L}^{-1} \mathrm{NiCl}_{2} \cdot 6 \mathrm{H}_{2} \mathrm{O}$ (Synth), and $45 \mathrm{~g} \mathrm{~L}^{-1} \mathrm{H}_{3} \mathrm{BO}_{3}$ (Fluka) [11]. The $\mathrm{pH}$ was adjusted to 5. This solution $\left(\mathrm{Ni}^{2+} 1.52 \mathrm{~mol} \mathrm{~L}^{-1}\right)$ was diluted (using a $45 \mathrm{~g} \mathrm{~L}^{-1}$ $\mathrm{H}_{3} \mathrm{BO}_{3}$ solution) down to a concentration of $10^{-5} \mathrm{~mol} \mathrm{~L}^{-1}$ $\mathrm{Ni}^{2+}$.

2.1.3. $\mathrm{Cr}^{3+}$ Solution. The stock electrolyte solution was prepared with Milli-Q water, $0.02 \mathrm{~mol} \mathrm{~L}^{-1} \mathrm{CrCl}_{3} \cdot 6 \mathrm{H}_{2} \mathrm{O}$ (Vetec), $10 \mathrm{~g} \mathrm{~L}^{-1} \mathrm{NH}_{4} \mathrm{Cl}$ (Synth), $14 \mathrm{~g} \mathrm{~L}^{-1} \mathrm{NaCl}$ (Synth), $20 \mathrm{~g} \mathrm{~L}^{-1}$ $\mathrm{H}_{3} \mathrm{BO}_{3}$ (Fluka), $30 \mathrm{~g} \mathrm{~L}^{-1}$ glycine (J.T.Baker), and $63 \mathrm{~g} \mathrm{~L}^{-1}$ methanol (Vetec) [12]. This solution was diluted (using the same solution as before, but with the absence of the chrome ions) down to a concentration of $10^{-5} \mathrm{~mol} \mathrm{~L}^{-1} \mathrm{Cr}^{3+}$.

2.1.4. $\mathrm{Mn}^{2+}$ Solution. The stock electrolyte solution was prepared with Milli-Q water, $0.1 \mathrm{~mol} \mathrm{~L}^{-1} \mathrm{MnSO}_{4} \cdot \mathrm{H}_{2} \mathrm{O}$ (Synth) water, and $0.1 \mathrm{~mol} \mathrm{~L}^{-1} \mathrm{Na}_{2} \mathrm{SO}_{4}$ (ISOFAR) [13]. In order to obtain the calibration curve, this solution was diluted (using $0.1 \mathrm{~mol} \mathrm{~L}^{-1} \mathrm{Na}_{2} \mathrm{SO}_{4}$ solution) down to a concentration of $10^{-6} \mathrm{~mol} \mathrm{~L}^{-1} \mathrm{Mn}^{2+}$.

\subsection{Apparatus}

2.2.1. Relaxometry Measurements. The measurements were performed in two equipment pieces:

(i) A $0.23 \mathrm{~T}$, TD-NMR spectrometer (Spinlock, Córdoba Argentine).

(ii) The home-built unilateral TD-NMR sensor (UNMR) with $0.33 \mathrm{~T}\left(14.2 \mathrm{MHz}\right.$ for $\left.{ }^{1} \mathrm{H}\right)$ constructed in a "Ushaped" geometry $[14,15]$.

2.2.2. Spectrophotometric Measurements. The Uv/Vis spectrometer used for these experiments was from PerkinElmer manufacturer, model LAMBDA 25. The measurements were performed in the wavelength range of $1000 \mathrm{~nm}$ to $600 \mathrm{~nm}$. The maximum absorption peaks were situated at 810,422 , and $394 \mathrm{~nm}$ for the aqueous solutions of $\mathrm{Cu}^{2+}, \mathrm{Cr}^{3+}$, and $\mathrm{Ni}^{2+}$, respectively.

\subsection{CPMG Parameters}

(i) Spinlock. The CPMG parameters were $\pi / 2$ and $\pi$ pulses with 6.2 and $12.4 \mu \mathrm{s}$, respectively. The echo time $(\tau)$ was equal to $2000 \mu \mathrm{s}$. The number of echoes differed for each sample but ranged from 400 to 2000 echoes. The recycling delay was $1.5 \mathrm{~ms}$ and 8 scans were performed.

(ii) UNMR. The CPMG parameters were $\pi / 2$ and $\pi$ pulses with 3 and $6 \mu \mathrm{s}$, respectively. The time between each refocusing pulse $(2 \tau)$ was $120 \mu \mathrm{s}, 2000$ echoes were used, the recycling delay was $500 \mathrm{~ms}$, and 300 scans were performed.

All measurements were performed at $25 \pm 0.5^{\circ} \mathrm{C}$. Seven curves were made for each ion; thereby the used value of $t_{95 \%}$ was 2,447 (Student's $t$-test). Each calibration curve had at least 7 points.

\section{Results and Discussion}

The confidence level used for the calculation of the validation parameters for the relaxometry was 95\% (Table 1). The validation parameters for the relaxometry technique, using the Spinlock and the UNMR, are shown in Table 1. To compare the relaxometry with the spectrophotometry (SP) the solutions of $\mathrm{Cu}^{2+}, \mathrm{Ni}^{2+}$, and $\mathrm{Cr}^{3+}$ were used due to their intense colors. The validation parameters for the SP are also in Table 1.

To calculate the limit of detection (LOD) and limit of quantification (LOQ) the following equations were used:

$$
\begin{aligned}
& \mathrm{LOD}=X+t_{95 \%} \sigma, \\
& \mathrm{LOQ}=X+10 \sigma,
\end{aligned}
$$

where $X$ is the average of the signals obtained for the blank solutions ( 7 measurements) and $\sigma$ is the standard deviation. The technique's sensitivity is given by the slope of the calibration curve.

The relaxometry measurements using the Spinlock showed the best results, with a lower $\operatorname{LOD}\left(\approx 10^{-6} \mathrm{~mol} \mathrm{~L}^{-1}\right)$ and LOQ $\left(\approx 10^{-5} \mathrm{~mol} \mathrm{~L}^{-1}\right)$ in comparison to the measurements obtained using the UNMR $\left(\approx 10^{-4}\right.$ and $\approx 10^{-3} \mathrm{~mol} \mathrm{~L}^{-1}$, resp.). The best efficiency of the Spinlock can be explained by the homogeneous magnetic field, which eliminates the diffusion effects that are present in the UNMR measurements. Another advantage of the Spinlock measurements is that the sample is fully analyzed while in the UNMR only a slice is analyzed (at a height of $3 \mathrm{~mm}$ above the sensor surface).

Despite the fact the UNMR has the highest LOQ, it has some advantages: it is an open system that allows the analysis of big samples; it is small and light (less than $2.5 \mathrm{~kg}$ ) which facilitates its transportation and it has a larger superior limit of quantification than the Spinlock.

The sensitivity of both spectrometers is similar, differing by approximately $15 \%$. These techniques showed the highest sensitivity towards $\mathrm{Mn}^{2+}$, which can be associated with the fact that the $\mathrm{Mn}^{2+}$ has more unpaired electrons than the other ions, which enhance the relaxation effect $[5,8]$. Therefore, manganese has the lowest LOQ $\left(\approx 10^{-6} \mathrm{~mol} \mathrm{~L}^{-1}\right.$ for Spinlock and $\approx 10^{-4} \mathrm{~mol} \mathrm{~L}^{-1}$ for UNMR).

The Spinlock and UNMR linear regression curves for ions $\mathrm{Ni}^{2+}, \mathrm{Cu}^{2+}, \mathrm{Cr}^{3+}$, and $\mathrm{Mn}^{2+}$ are shown in Figure 1. The figure is a plot of the ion concentration $\left(\mathrm{mol} \mathrm{L}^{-1}\right)$ versus $R_{2}\left(\mathrm{~s}^{-1}\right)$, 
TABLE 1: Validation parameters for relaxometry and spectrophotometry techniques.

\begin{tabular}{|c|c|c|c|c|c|}
\hline & Ion & $\mathrm{LOD}\left(\mathrm{mol} \mathrm{L}^{-1}\right)$ & LOQ $\left(\mathrm{mol} \mathrm{L}^{-1}\right)$ & Sensitivity $^{\mathrm{a}}$ & Linearity range $\left(\mathrm{mol} \mathrm{L}^{-1}\right)$ \\
\hline \multirow{4}{*}{ Spinlock } & $\mathrm{Ni}^{2+}$ & $3.9 \times 10^{-6}$ & $3.5 \times 10^{-5}$ & $572 \pm 3^{b}$ & $3.5 \times 10^{-5}$ to $1.5 \times 10^{-1}$ \\
\hline & $\mathrm{Cu}^{2+}$ & $8.5 \times 10^{-6}$ & $3.5 \times 10^{-5}$ & $1401 \pm 8^{\mathrm{b}}$ & $3.5 \times 10^{-5}$ to $1.0 \times 10^{-1}$ \\
\hline & $\mathrm{Cr}^{3+}$ & $3.3 \times 10^{-6}$ & $1.4 \times 10^{-5}$ & $7370 \pm 158^{\mathrm{b}}$ & $1.4 \times 10^{-5}$ to $1.0 \times 10^{-2}$ \\
\hline & $\mathrm{Mn}^{2+}$ & $1.1 \times 10^{-6}$ & $4.6 \times 10^{-6}$ & $31487 \pm 282^{\mathrm{b}}$ & $4.6 \times 10^{-6}$ to $5.0 \times 10^{-2}$ \\
\hline \multirow{4}{*}{ UNMR } & $\mathrm{Ni}^{2+}$ & $3.1 \times 10^{-3}$ & $1.3 \times 10^{-2}$ & $632 \pm 4^{\mathrm{b}}$ & $1.3 \times 10^{-2}$ to $7.5 \times 10^{-1}$ \\
\hline & $\mathrm{Cu}^{2+}$ & $1.3 \times 10^{-3}$ & $5.0 \times 10^{-3}$ & $1141 \pm 8^{\mathrm{b}}$ & $5.0 \times 10^{-3}$ to $5.0 \times 10^{-1}$ \\
\hline & $\mathrm{Cr}^{3+}$ & $3.5 \times 10^{-4}$ & $1.7 \times 10^{-3}$ & $9470 \pm 130^{\mathrm{b}}$ & $1.7 \times 10^{-3}$ to $1.4 \times 10^{-1}$ \\
\hline & $\mathrm{Mn}^{2+}$ & $5.7 \times 10^{-5}$ & $2.3 \times 10^{-4}$ & $28517 \pm 294^{\mathrm{b}}$ & $2.3 \times 10^{-4}$ to $1.0 \times 10^{-1}$ \\
\hline \multirow{3}{*}{ SP } & $\mathrm{Ni}^{2+}$ & $1.3 \times 10^{-4}$ & $5.2 \times 10^{-4}$ & $5.01 \pm 0.01^{c}$ & $5.2 \times 10^{-4}$ to $2.0 \times 10^{-2}$ \\
\hline & $\mathrm{Cu}^{2+}$ & $1.0 \times 10^{-3}$ & $3.6 \times 10^{-3}$ & $12.46 \pm 0.04^{\mathrm{c}}$ & $3.6 \times 10^{-3}$ to $8.0 \times 10^{-2}$ \\
\hline & $\mathrm{Cr}^{3+}$ & $7.7 \times 10^{-4}$ & $3.2 \times 10^{-3}$ & $16.28 \pm 0.29^{c}$ & $3.2 \times 10^{-3}$ to $5.9 \times 10^{-2}$ \\
\hline
\end{tabular}

${ }^{\mathrm{a}}$ Mean $\pm \mathrm{SD}(n=7) ; \mathrm{s}^{-1} \mathrm{~mol}^{-1} \mathrm{~L}^{\mathrm{c}} \mathrm{cm}^{-1} \mathrm{~mol}^{-1} \mathrm{~L}$.

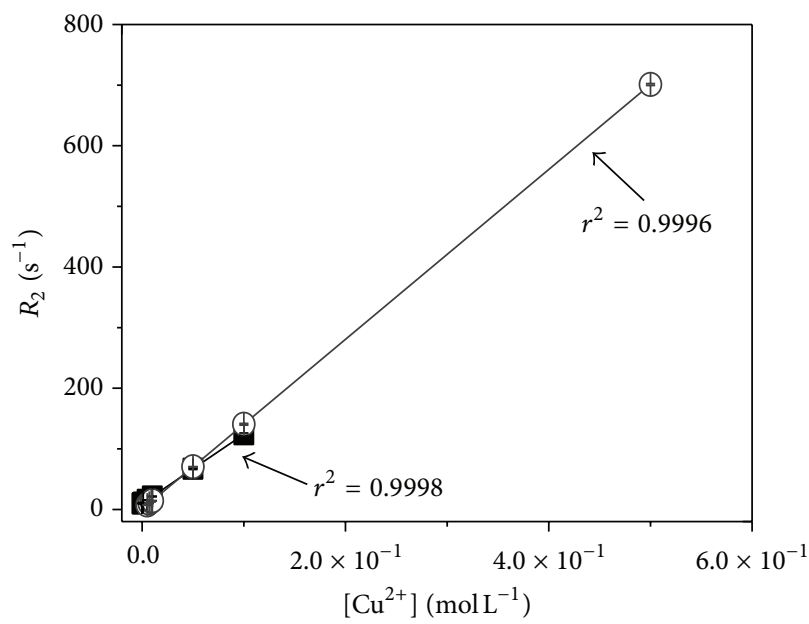

(a)

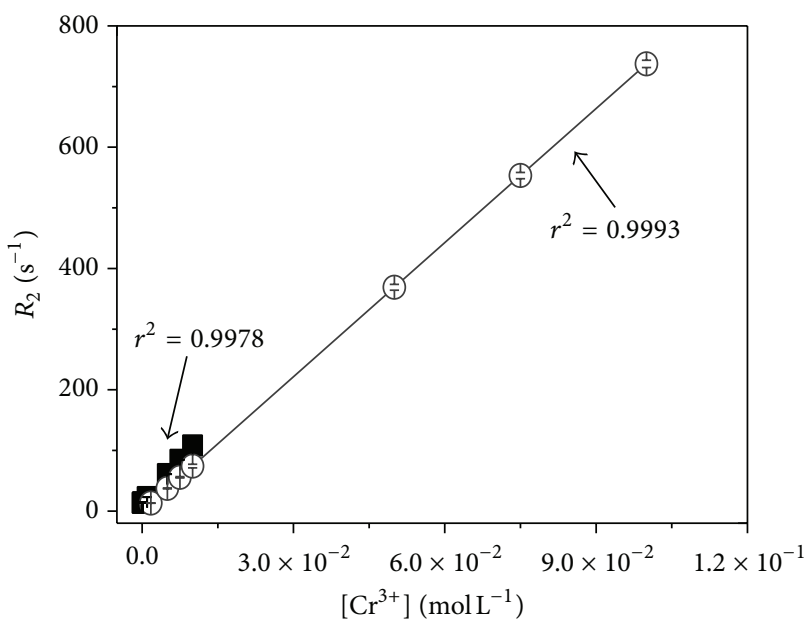

(c)

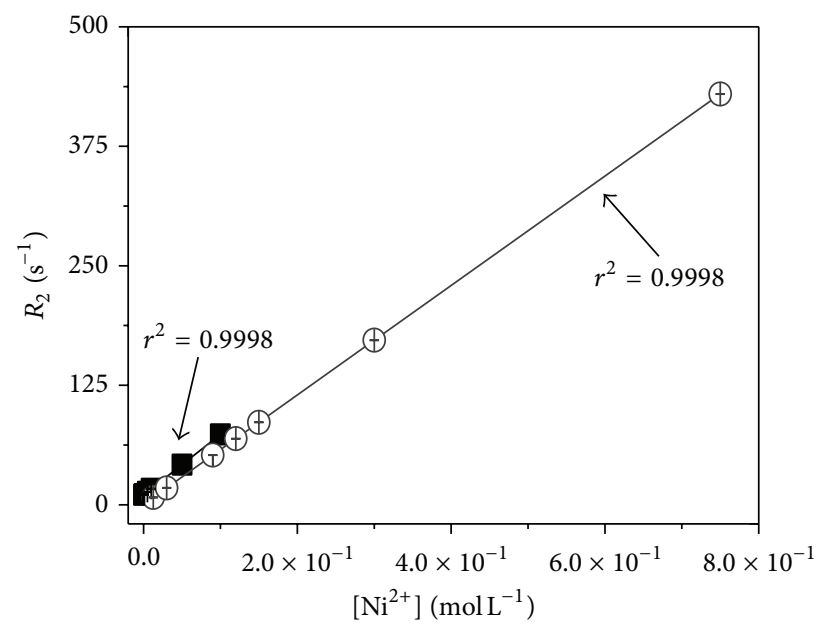

(b)

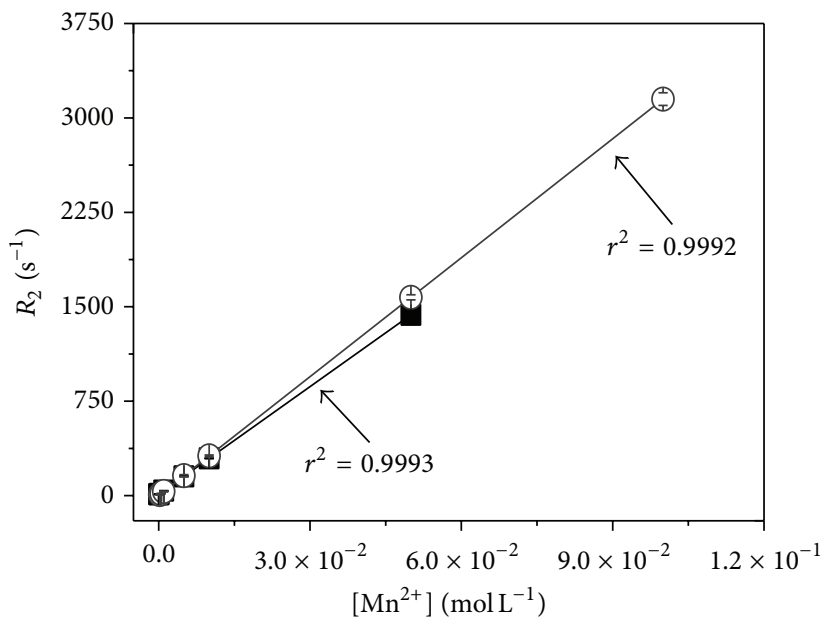

(d)

FIGURE 1: Calibration curves for relaxometry obtained using the Spinlock (it is represented by the symbol $\mathbf{\square}$ ) and the UNMR (it is represented by the symbol $\bigcirc$ ). Each curve was made 7 times and the average is represented in the figure. The ions $\mathrm{Cu}^{2+}, \mathrm{Ni}^{2+}, \mathrm{Cr}^{3+}$, and $\mathrm{Mn}^{2+}$ are represented by (a), (b), (c), and (d), respectively. 
TABLE 2: Linear regression parameters for relaxometry and spectrophotometry calibration curves.

\begin{tabular}{lcccc}
\hline & Ion & Slope $^{\mathrm{a}}$ & Intercept $^{\mathrm{a}}$ & $r^{2}$ \\
\hline \multirow{4}{*}{ Spinlock $^{\mathrm{b}}$} & $\mathrm{Ni}^{2+}$ & $572 \pm 3$ & $0.404 \pm 0.001$ & 0.9998 \\
& $\mathrm{Cu}^{2+}$ & $1491 \pm 8$ & $0.402 \pm 0.002$ & 0.9998 \\
& $\mathrm{Cr}^{3+}$ & $7370 \pm 158$ & $0.420 \pm 0.010$ & 0.9978 \\
& $\mathrm{Mn}^{2+}$ & $31487 \pm 282$ & $0.405 \pm 0.003$ & 0.9993 \\
\hline \multirow{4}{*}{$\mathrm{NNMR}^{\mathrm{b}}$} & $\mathrm{Ni}^{2+}$ & $632 \pm 4$ & $10.4 \pm 0.1$ & 0.9998 \\
& $\mathrm{Cu}^{2+}$ & $1141 \pm 8$ & $10.0 \pm 0.3$ & 0.9996 \\
& $\mathrm{Cr}^{3+}$ & $9570 \pm 130$ & $13.4 \pm 0.2$ & 0.9993 \\
& $\mathrm{Mn}^{2+}$ & $28517 \pm 294$ & $10.3 \pm 0.3$ & 0.9992 \\
$\mathrm{SP}^{\mathrm{c}}$ & $\mathrm{Ni}^{2+}$ & $5.01 \pm 0.01$ & $0.0004 \pm 0.0003$ & 0.9999 \\
& $\mathrm{Cu}^{2+}$ & $12.45 \pm 0.04$ & $0.005 \pm 0.002$ & 0.9999 \\
& $\mathrm{Cr}^{3+}$ & $16.28 \pm 0.29$ & $0.0365 \pm 0.0513$ & 0.9991 \\
\hline
\end{tabular}

${ }^{\mathrm{a}}$ Mean $\pm \mathrm{SD}(n=7) ;{ }^{\mathrm{b}} R_{2}=$ intercept + slope[ion], where $R_{2}\left(\mathrm{~s}^{-1}\right)$ is the inverse of $T_{2}$ and the ion concentration is given in $\mathrm{mol} \mathrm{L}^{-1} ;{ }^{\mathrm{c}} A\left(\lambda_{810 \mathrm{~nm}}\right)=$ intercept + slope[ion], where $A$ is the absorbance in 810,422 , and $394 \mathrm{~nm}$ for $\mathrm{Cu}^{2+}, \mathrm{Cr}^{3+}$, and $\mathrm{Ni}^{2+}$, respectively, and the ion concentration is given in $\mathrm{mol} \mathrm{L}{ }^{-1}$.

which is the inverse of $T_{2}$. The parameters of the regression curves are displayed in Table 2 for Spinlock, UNMR, and SP.

It is possible to note a large difference in the intercept value between both techniques $\left(\approx 0.4 \mathrm{~s}^{-1}\right.$ for spinlock and $\approx 10 \mathrm{~s}^{-1}$ for UNMR). This difference can be attributed to the diffusion effects that take place during the UNMR measurements. Since nothing is truly stationary in a solution and the UNMR spectrometer possesses such a large magnetic field gradient, the movement of the particles towards a different location and different magnetic field strength attenuates the measured signal [16] and the apparent relaxation time (which is different from the true relaxation time of the sample) and, thus, increases the value of the intercept of the curves.

Furthermore, by comparing the intercept value throughout the same technique but for different ions, a slight difference is noted for the $\mathrm{Cr}^{3+}$ ions. This difference can be explained in light of the different additives used in the chromium solution which affect the relaxation time of the sample by reducing it. This shows that the composition of the matrix must be taken into account when performing relaxometric measurements, as they can influence the relaxation time of the sample.

As expected, for $\left(\mathrm{Cu}^{2+}\right)_{\mathrm{aq}}$ the LOQ $\left(\approx 10^{-3} \mathrm{~mol} \mathrm{~L}^{-1}\right)$ for $\mathrm{SP}$ is higher than the relaxometry technique using Spinlock $\left(\approx 10^{-5} \mathrm{~mol} \mathrm{~L}^{-1}\right)$. Furthermore, the SP can be used only for quantification of compounds which have absorption bands in the UV-Visible region; because of this the $\left(\mathrm{Mn}^{2+}\right)_{\mathrm{aq}} \mathrm{con}-$ centration cannot be determined by this technique without a pretreatment of the sample [17].

Another technique commonly used for quantification of ions is the Atomic Absorption Spectrometry (AAS), which has the advantage of being selective, but the disadvantage is its high cost of operation and maintenance of the equipment in addition to having a limitation on the viscosity of the solvent. The LOQ for the measurements performed in the Spinlock spectrometer is approximately of one order of magnitude
TABLE 3: Comparison between the LOQs for atomic absorption spectroscopy and relaxometry [10].

\begin{tabular}{lcc}
\hline Element & $\begin{array}{c}\text { AAS } \\
\text { LOQ }\left(\mathrm{mol} \mathrm{L}^{-1}\right)^{*}\end{array}$ & $\begin{array}{c}\text { Relaxometry Spinlock } \\
\text { LOQ }\left(\mathrm{mol} \mathrm{L}^{-1}\right)\end{array}$ \\
\hline $\mathrm{Ni}$ & $1.7 \times 10^{-6}$ & $3.5 \times 10^{-5}$ \\
$\mathrm{Cu}$ & $4.7 \times 10^{-7}$ & $3.5 \times 10^{-5}$ \\
$\mathrm{Cr}$ & $1.2 \times 10^{-6}$ & $1.4 \times 10^{-5}$ \\
$\mathrm{Mn}$ & $3.6 \times 10^{-7}$ & $4.6 \times 10^{-6}$ \\
\hline
\end{tabular}

${ }^{*}$ Values determined for the respective wavelengths: 232; 324.7; 537.9; and $279.5 \mathrm{~nm}$ for $\mathrm{Ni}, \mathrm{Cu}, \mathrm{Cr}$, and $\mathrm{Mn}$, respectively [10].

larger than AAS, as shown in Table 3 [10]. It is worth noting that the relaxometry technique is only sensitive to paramagnetic species and metal ions, whereas AAS is not as selective and is able to detect both metal atoms and metal ions.

Another advantage of relaxometry is that it is a nondestructive and robust technique. It can be used in solution when the solvents have high-viscosity and it does not require chemical indicators or support electrolytes [3].

A disadvantage of relaxometry is that other species in the solution, such as complexants and other paramagnetic species, can interfere with the analysis [18]. When constructing a calibration curve the matrix composition must be taken into consideration. In addition, this technique is not selective.

However, this technique has low cost of operation and maintenance, it does not require specialists for its operation, and it is a good option for use in rapid analysis and for coupling with other techniques.

A possible application of this technique is to quantify ions in residual effluents of electroplating industry and other chemical residues in a simple and fast way. The relaxometry technique could be applied to evaluate the corrosion of metallic surfaces.

\section{Conclusions}

With this work we have demonstrated that the relaxometry technique performed with the Spinlock spectrometer has a lower LOQ than the one performed with UNMR. This can be explained by the homogeneous magnetic field of the Spinlock, which eliminates diffusion effects. Nevertheless, UNMR has the advantage of being an open system, which does not limit sample size.

UNMR has proven to be better than SP, as it is able to detect paramagnetic ions without sample pretreatment, which is the case with SP when analyzing, for example, $\mathrm{Mn}^{2+}$ ions.

The LOQ obtained through the Spinlock spectrometer is of one order of magnitude larger than the one found with AAS $\left(10^{-5} \mathrm{~mol} \mathrm{~L}^{-1}\right.$ for Spinlock against $10^{-6} \mathrm{~mol} \mathrm{~L}^{-1}$ for AAS) but has the advantage of being a much cheaper and more robust technique than AAS.

In conclusion TD-NMR can be used as an alternative method to some quantification techniques, such as AAS and SP, due to its fast analyses, easy handling, and no need for sample pretreatment. 


\section{Competing Interests}

The authors declare that they have no competing interests.

\section{Acknowledgments}

The work described in this paper was financially supported by FAPESP (Process no. 2012/22281-9), CNPq PIBIC (Process no. 134696/2014-0), and CNPq (Process nos. 1421862 and $161555 / 2015-2)$.

\section{References}

[1] B. F. Gomes, L. M. S. Nunes, C. M. S. Lobo, L. F. Cabeça, and L. A. Colnago, "In situ study of the magnetoelectrolysis phenomenon during copper electrodeposition using time domain NMR relaxometry," Analytical Chemistry, vol. 86, no. 19, pp. 9391-9393, 2014.

[2] B. F. Gomes, L. M. S. Nunes, C. M. S. Lobo, A. S. Carvalho, L. F. Cabeça, and L. A. Colnago, "In situ analysis of copper electrodeposition reaction using unilateral NMR sensor," Journal of Magnetic Resonance, vol. 261, pp. 83-86, 2015.

[3] P. F. Cobra, B. F. Gomes, C. I. N. Mitre, L. L. Barbosa, L. V. Marconcini, and L. A. Colnago, "Measuring the solubility product constant of paramagnetic cations using time-domain nuclear magnetic resonance relaxometry," Microchemical Journal, vol. 121, pp. 14-17, 2015.

[4] L. M. S. Nunes, P. F. Cobra, L. F. Cabeça, L. L. Barbosa, and L. A. Colnago, "In situ quantification of $\mathrm{Cu}(\mathrm{II})$ during an electrodeposition reaction using time-domain NMR relaxometry," Analytical Chemistry, vol. 84, no. 15, pp. 6351-6354, 2012.

[5] P. A. Vasilev, S. V. Vasilev, A. L. Ivanov, and V. A. Khalapsin, "NMR analyzer of aqueous-solutions of paramagnetic metalions," Instruments and Experimental Techniques, vol. 37, no. 5, pp. 636-641, 1994.

[6] A. N. Glebov, M. V. Khokhlov, and N. E. Zhuravleva, "Structural-dynamic properties of chromium(III) aqua complex," Zhurnal Neorganicheskoi Khimii, vol. 38, no. 4, pp. 645646, 1993.

[7] N. Bloembergen, E. M. Purcell, and R. V. Pound, "Relaxation effects in nuclear magnetic resonance absorption," Physical Review, vol. 73, no. 7, pp. 679-712, 1948.

[8] R. A. Bernheim, T. H. Brown, H. S. Gutowsky, and D. E. Woessner, "Temperature dependence of proton relaxation times in aqueous solutions of paramagnetic ions," The Journal of Chemical Physics, vol. 30, no. 4, pp. 950-956, 1959.

[9] B. Yuan, C. Wang, L. Li, and S. Chen, "Investigation of the effects of the magnetic field on the anodic dissolution of copper in $\mathrm{NaCl}$ solutions with holography," Corrosion Science, vol. 58, pp. 69-78, 2012.

[10] Agilent Technologies, Flame Atomic Absorption Spectrometry Analytical Methods, 2015.

[11] A. Chiba, K. Kitamura, and T. Ogawa, "Magnetic field effects on the electrodeposition of nickel from a high $\mathrm{pH}$ watt's bath," Surface and Coatings Technology, vol. 27, no. 1, pp. 83-88, 1986.

[12] G. Saravanan and S. Mohan, "Corrosion behavior of Cr electrodeposited from $\mathrm{Cr}(\mathrm{VI})$ and $\mathrm{Cr}(\mathrm{III})$-baths using direct (DCD) and pulse electrodeposition (PED) techniques," Corrosion Science, vol. 51, no. 1, pp. 197-202, 2009.

[13] P. Ilea, I. C. Popescu, M. Urda, and L. Oniciu, "The electrodeposition of manganese from aqueous solutions of $\mathrm{MnSO}_{4}$. IV: electrowinning by galvanostatic electrolysis," Hydrometallurgy, vol. 46, no. 1-2, pp. 149-156, 1997.

[14] B. Blümich, J. Perlo, and F. Casanova, "Mobile single-sided NMR," Progress in Nuclear Magnetic Resonance Spectroscopy, vol. 52, no. 4, pp. 197-269, 2008.

[15] L. F. Cabeça, L. V. Marconcini, G. P. Mambrini, R. B. V. Azeredo, and L. A. Colnago, "Monitoring the transesterification reaction used in biodiesel production, with a low cost unilateral nuclear magnetic resonance sensor," Energy \& Fuels, vol. 25, no. 6, pp. 2696-2701, 2011.

[16] J. Keeler, Understanding NMR Spectroscopy, John Wiley \& Sons, Chichester, UK, 2005.

[17] R. Kripal and A. K. Shukla, "Absorption spectrum of Mn2+ ions doped in diammonium hexaaquamagnesium(II) sulfate," Pramana-Journal of Physics, vol. 65, no. 1, pp. 153-157, 2005.

[18] F. V. C. Kock and L. A. Colnago, "Rapid and simultaneous relaxometric methods to study paramagnetic ion complexes in solution: an alternative to spectrophotometry," Microchemical Journal, vol. 122, pp. 144-148, 2015. 

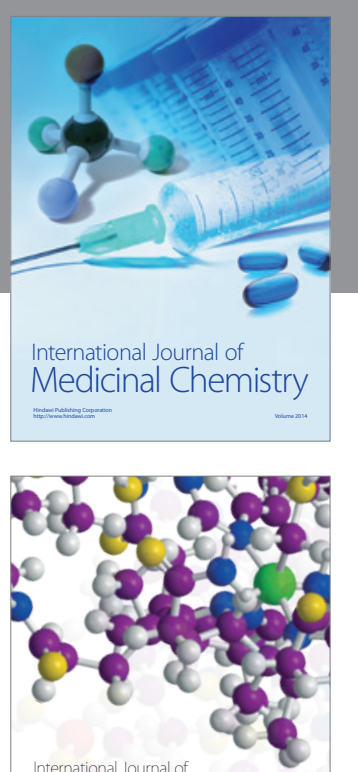

Carbohydrate Chemistry

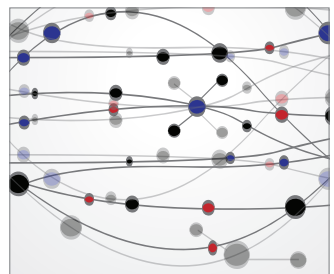

The Scientific World Journal
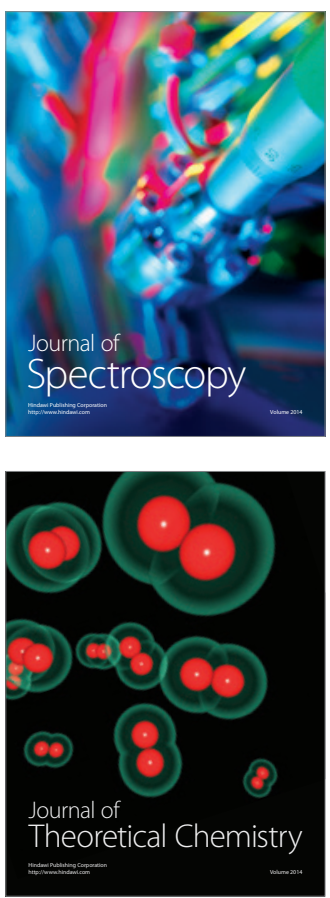
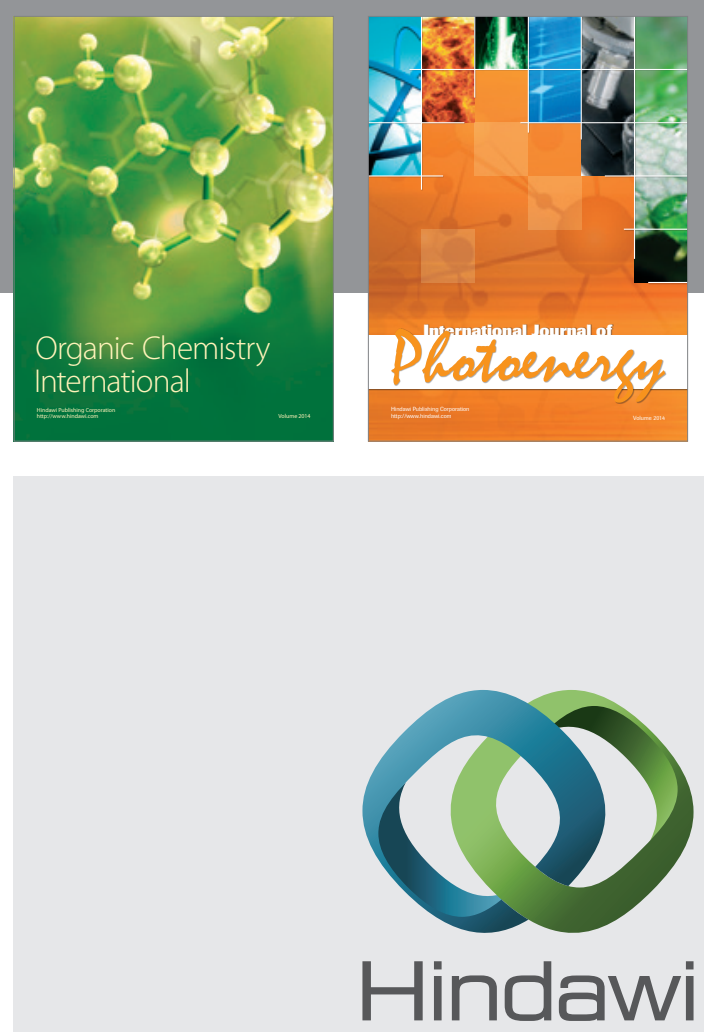

Submit your manuscripts at

http://www.hindawi.com

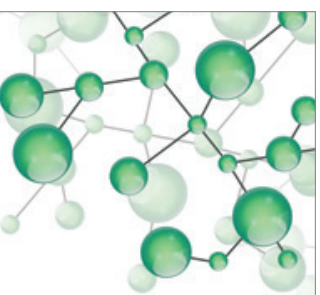

International Journal of

Inorganic Chemistry

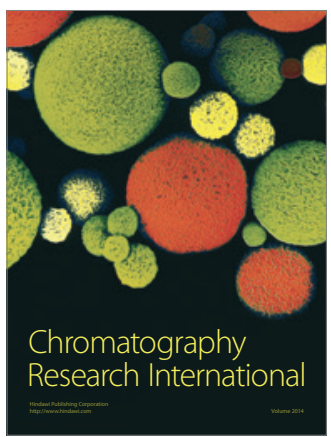

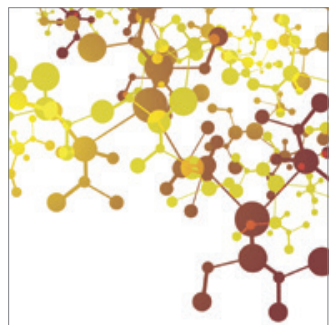

Applied Chemistry
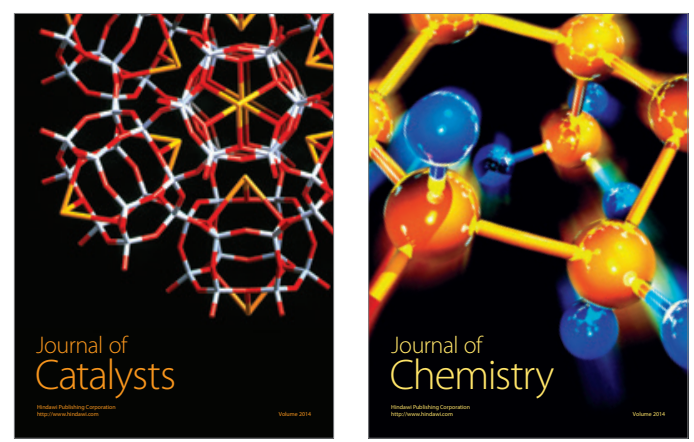
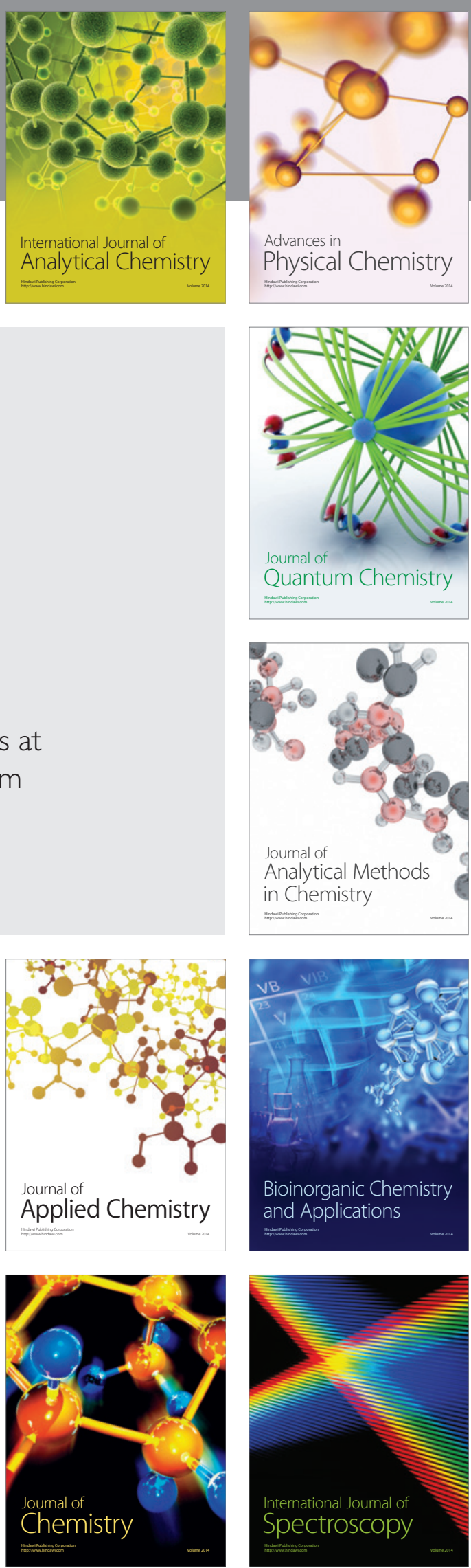